\title{
Sex Differences in the Dorsolateral Telencephalon Correlate with Home Range Size in Blenniid Fish
}

\author{
Silvia S. Costa ${ }^{a}$ Rui Andrade ${ }^{a}$ Luis A. Carneiro ${ }^{a}$ Emanuel J. Gonçalves ${ }^{a}$ \\ Kurt Kotrschal $^{c}$ Rui F. Oliveira ${ }^{a, b}$ \\ aEco-Ethology Research Unit, ISPA - Instituto Universitário, Lisbon, and ${ }^{\mathrm{b}}$ Champalimaud Neuroscience \\ Programme, Instituto Gulbenkian de Ciência, Oeiras, Portugal; ' Konrad Lorenz Institute, Grünau, Austria
}

\section{Key Words}

Blennies · Spatial behavior - Sexual dimorphism •

Hippocampal pallium $\cdot$ Teleost fish

\begin{abstract}
Blenniid fish exhibit a polygynandric mating system with parental care restricted to males. Nest-holder males defend a breeding territory centered on their nest, usually a crevice or hole in a rocky substrate, to which they attract females to spawn. Females, on the other hand, must search for nests in order to spawn and usually are the choosy sex, producing several sequential egg batches and broods during the breeding season. Therefore, male blennies are more site-attached than females. This situation offers an opportunity to investigate potential neural correlates of intraspecific differences in selective pressures for different spatial abilities in these species. Since the dorsolateral telencephalon has been considered a teleost homologue of the mammalian hippocampus, we predicted that the spatial abilities required for females to locate and return accurately to nests of males may have produced a sex difference in the size of the telencephalic nuclei involved in spatial abilities, biased towards females. To test this hypothesis, we assessed the home ranges and measured the size of the dorsolateral telencephalon of both sex-
\end{abstract}

es during the breeding season in two blenniid species, the shanny (Lipophrys pholis) and the Azorean rock-pool blenny (Parablennius parvicornis). We chose these two species because they differ in the degree of chemical communication they use, and this could also lead to differences in telencephalic areas. As predicted, in both species females present considerably larger home ranges paralleled by larger dorsolateral ventral telencephalic nuclei (DLv) than males. Other telencephalic nuclei that were measured did not show any sex difference in size. These results suggest that the DLv is involved in spatial abilities in blenniid fish and that sexual selection may be promoting this divergence as already described for mammals and birds.

Copyright $\odot 2011$ S. Karger AG, Basel

\section{Introduction}

Ecological conditions and navigational demands are known to reflect the spatial strategies used by animals [Odling-Smee et al., 2006] and to shape the underlying neuroanatomy of the brain [Kotrschal and Palzenberger, 1992; Kotrschal et al., 1998; Shumway, 2008]. One of the best documented cases in neuroecology is the relationship between spatial ability requirements and the relative

\section{KARGER}

Fax +41613061234

E-Mail karger@karger.ch

www.karger.com
(C) 2011 S. Karger AG, Basel

0006-8977/11/0771-0055\$38.00/0

Accessible online at:

www.karger.com/bbe
Silvia Costa

Eco-Ethology Research Unit, ISPA

Rua Jardim do Tabaco 34

PT-1149-041 Lisboa (Portugal)

Tel. +351 21881 1700, Fax +351 21886 0954, E-Mail scosta@ispa.pt 


\begin{tabular}{ll}
\hline \multicolumn{2}{l}{ Abbreviations used in this paper } \\
\hline BO & bulbus olfactorius \\
CA & commissura anterior \\
Dc & area dorsalis telencephali pars centralis \\
Dd & area dorsalis telencephali pars dorsalis \\
DLd & dorsal subdivision of area dorsalis telencephali lateralis \\
DLv & ventral subdivision of area dorsalis telencephali lateralis \\
Dm & area dorsalis telencephali pars medialis \\
Dp & area dorsalis telencephali pars posterior \\
E & nucleus entopenduncularis \\
N Olf Ant & nucleus olfactorius anterior \\
Nt & nervus terminalis (nucleus olfactorectinalis) \\
POA & preoptic area \\
Vc & area ventralis telencephali pars centralis \\
Vd & area ventralis telencephali pars dorsalis \\
Vi & area ventralis telencephali pars intermedia \\
Vl & area ventralis telencephali pars lateralis \\
Vp & area ventralis telencephali pars postcommissuralis \\
Vs & area ventralis telencephali pars supracommissuralis \\
Vv & area ventralis telencephali pars ventralis \\
\hline
\end{tabular}

development of specific neural substrates for spatial cognition, such as the hippocampus in mammals, or other medial pallium homologues in other vertebrate taxa [Jacobs, 2009]. Examples come from mammals [Jacobs et al., 1990; Galea et al., 1996], birds [Sherry et al., 1993; Reboreda et al., 1996; Hoshooley and Sherry, 2007], reptiles [Day et al., 1999a, b, 2001], and fish [Sovrano et al., 2003; Pollen et al., 2007] revealing striking patterns of sex, season, species and/or population differences [Jacobs, 2009].

Sex differences in spatial cognition have been detected both in vertebrates and in invertebrates [e.g. Gaulin and FitzGerald, 1986, 1989; Jozet-Alves et al., 2008] and can be explained by sexual selection if increments in spatial ability had a greater effect on the mating success of one sex than the other [Puts et al., 2007]. Gaulin and FitzGerald $[1986,1989]$ were the first to predict the link between mating system and spatial cognition. Their work in voles (genus Microtus) showed that breeding males of polygamous species have home range sizes 4-5 times larger than those of females, while monogamous species lack such sex differences in ranging behavior, since males and females defend a joint territory. Later Jacobs et al. [1990] made the link between mating system type and the relative volume of the hippocampus in voles, where only in polygamous species the hippocampus of males is enlarged relative to the entire brain. Similar findings were observed in birds. In the brown-headed cowbird, a nest parasite where females must find host nests, females have relatively larger hippocampi than males, whereas in polygynous species, where males and females do not differ in space use, the hippocampal volume was not dimorphic [Sherry et al., 1993]. Therefore, the direction of dimorphism could be predicted by the sex-specific mating behavior.

Sex differences are known to have seasonal patterns for several species of birds and mammals, in which larger dispersal areas are associated with larger hippocampus in a specific sex only during the breeding season [Galea et al., 1996; Jacobs, 1996; Clayton et al., 1997; Galea and McEwen, 1999; Lavenex et al., 2000a, b]. In fish correlations between environmental complexity, social organization (mating system) and brain structures were recently reported for African cichlids [Pollen et al., 2007]. In a cichlid fish, sexually distinct performances have also been observed using a spatial maze, with males outperforming females in a cichlid fish [Sovrano et al., 2003]. However, data on the relationship between the occurrence of sexually distinct dispersal patterns and sexual dimorphisms in putative areas of the central nervous system involved in spatial cognition are still lacking for teleosts.

Blenniids provide a good model for the study of sex differences in spatial cognition in fish since during the breeding season the spatial behavior is distinct between the sexes. Parental males are known to be highly site-attached to a nest waiting for females to spawn and providing parental care to the eggs [Neat and Lengkeek, 2009]. Females, on the other hand, visit several nest sites during the breeding season having higher mobility rates than males and exploring larger areas [Santos, 1986; Santos et al., 1989, 1995]. Since blenniid females do not establish territories and explore larger areas than males in search for mates, one can hypothesize the occurrence of sex differences in brain regions involved in spatial memory was biased towards females. Studies in goldfish revealed that the dorsolateral ventral region of the telencephalon (DLv) is involved in the processing of spatial learning and memory [Vargas et al., 2000; Portavella et al., 2002; Rodríguez et al., 2002; Vargas et al., 2006] and considered homologous to the hippocampus of amniotes [Bradford, 1995; Wullimann and Mueller, 2004; Northcutt, 2006, 2008]. Thus, it is expected that sex differences in spatial behavior in blennies should be paralleled by sex differences in the size of the ventral area of the dorsolateral telencephalon.

We tested this hypothesis in two closely related blenniid species [Almada et al., 2005] (see fig. 1) which live in the same habitat (the intertidal zone of exposed rocky 


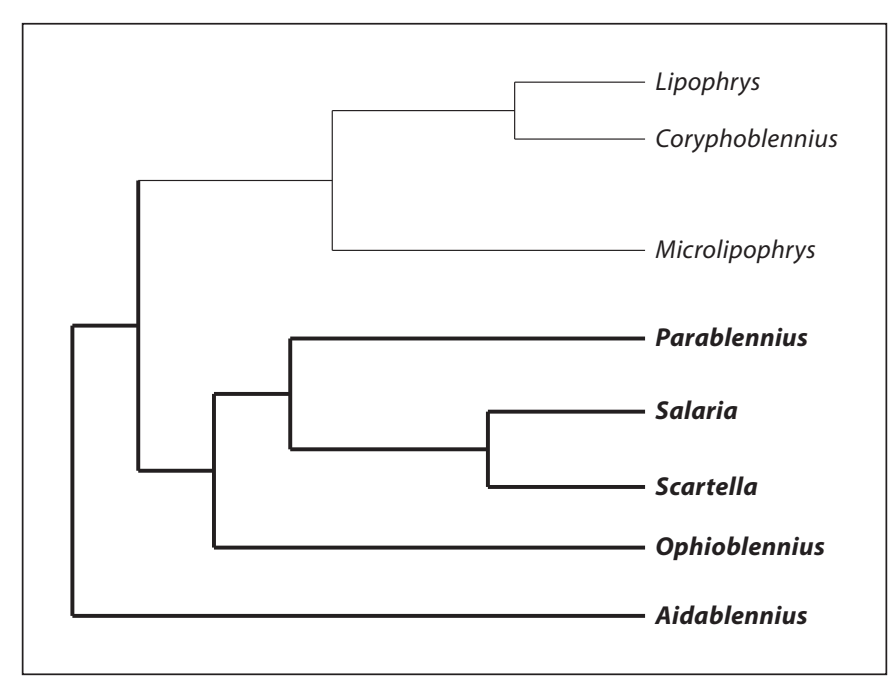

Fig. 1. Phylogenetic tree of the north-eastern Atlantic and Mediterranean blenniids (genera). Thick lines indicate the presence of anal glands [adapted from Almada et al., 2005].

shores): the Azorean rock-pool blenny (Parablennius parvicornis) and the shanny (Lipophrys pholis). The rationale for the use of this pair of species is that sex differences in the size of the ventral area of the dorsolateral telencephalon could also be explained as an adaptation for the processing of sex pheromones, since sex pheromone-producing anal glands are present in some blenniid lineages [Laumen et al., 1974; Zander, 1975; Barata et al., 2008] and secondary olfactory projections throughout the whole telencephalon are known to occur in teleosts [Finger, 1980; Davis et al., 1981; Rooney et al., 1992; Eisthen, 1997]. The DLv specifically receives olfactory input in several species, namely in goldfish [von Bartheld et al., 1984], cod [Rooney et al., 1992] and channel catfish [Bass, 1981]. Moreover, several lines of evidence suggest that this area is one of the targets of the secondary olfactory tracts that mediates reproductive behavior in goldfish [Weltzien et al., 2003 and references therein].

Since in some blennid species, males present anal glands, females of these species could also have acquired brain specializations for pheromone processing (i.e. a coevolution between the production of the pheromone signal by males and its processing by females). Therefore, we chose one species (the rock-pool blenny) with anal glands and one species that lacks these glands (the shanny) in order to determine the relative contribution of chemical communication and spatial cognition for the expected sex differences in the size of the ventral area of the dorsolateral telencephalon.

Sex Differences in the Dorsolateral

Telencephalon in Blenniid Fish
The following alternative hypotheses can be expected:

(1) If we observe a female-biased sex difference in the ventral area of the dorsolateral telencephalon of the rockpool blenny that is not present in the shanny, it should be due to a specialization in pheromone processing.

(2) If we detect a female-biased sex difference in the ventral area of the dorsolateral telencephalon in both species, then it should be seen as a specialization for spatial cognition, and pheromone processing should not be invoked as the causal explanation.

To test these hypotheses, we have not only measured telencephalic nuclei but also the size of the nucleus olfactorius anterior of the olfactory bulb that is predicted to be more developed in females of the species with pheromone communication.

\section{Materials and Methods}

\section{Animals and Study Sites}

We have studied the rock-pool blenny P. parvicornis at Faial Island, Azores, Portugal. The home range observations for this species were conducted in a 400-meter line shore of the tidal platform of Feteira at the south coast of Faial. To avoid interference with the behavioral observations, the collection of specimens to be killed for brain measurements was done at a similar rocky area $2 \mathrm{~km}$ east from Feteira. The shanny (L. pholis) was studied in mainland Portugal at two different sites: (a) specimens for brain measurements were collected at the tidal platforms of Mexilhoeira and Cabo Raso (Cascais, Portugal), and (b) observations for the calculation of home ranges were performed at the Arrábida Marine Park between the beaches of Alpertuche and Pilotos (Setúbal, Portugal). During the experimental procedure the 'Association for the Study of Animal Behaviour (ASAB) guidelines for the use of animals in research' were applied.

\section{Home Ranges}

We used two different methods for the computation of home ranges in $P$. parvicornis and in L. pholis, and therefore the data cannot be compared between the two species.

We caught and marked 73 individuals of $P$. parvicornis (60 females and 13 males) during low tide. In addition, 44 males recognized individually using a combination of individual marks (e.g. scars), relative size differences and nest location were also used in this study. Animals were followed on a daily basis in subsequent low tides for 60 days during two consecutive breeding seasons (June/July 1998 and 1999). Individuals were tagged with a combination of three plastic color beads inserted at the base of the dorsal fin following the method described by Patzner [1984], and previously proved successful in this species [Taborsky and Limberger, 1980; Santos et al., 1989]. All the tide pools and the nests inside them present in the study area, a 400-meter rocky shore front (transect), were mapped and followed on a daily basis during the 2 months of the field study. Every day during low tide we conducted scan observations during which the location of each individual was recorded in a map of the area. Distances between refer- 
ence points were taken to the nearest centimeter. Home ranges are expressed as the maximum distance between two points where the same individual has been spotted. Because males are more site-attached than females, we collected home range data for 34 males but only for 6 females.

In L. pholis we performed underwater animal focal observations while scuba diving during high tide and the maximum distance where the same individual was spotted was recorded. Individual nest-holder males were recognized using a combination of individual marks (e.g. scars), relative size differences and nest location. Females were identified by size and distinctive features (e.g. scars). These observations were done during the peak of the breeding season of L. pholis (males: $\mathrm{n}=22$, during March and April 1986, 1987 and 1993; females: $n=24$, during March 1993). Observation time ranged from 6 to $20 \mathrm{~min}$ for females and from 13 and $120 \mathrm{~min}$ for males. No correlation was found between observation time and recorded distance for each sex (males: $r=0.22$; females: $r=-0.05)$. Therefore, comparisons of the distances were used to further analyze differences between the sexes, independently of the time of observation.

\section{Measurement of Brain Regions}

Brain measurements were taken from sexually active adult males [ $\mathrm{n}=5$; standard length $(\mathrm{SL})=12.46 \pm 0.68 \mathrm{~cm}$; weight $=$ $27.99 \pm 5.18 \mathrm{~g}]$ and females $(\mathrm{n}=5 ; \mathrm{SL}=10.26 \pm 0.52 \mathrm{~cm}$; weight $=16.54 \pm 3.2 \mathrm{~g}$ ) of the rock-pool blenny P. parvicornis and for sexually mature males $(\mathrm{n}=5 ; \mathrm{SL}=10.9 \pm 0.79 \mathrm{~cm}$; weight $=$ $23.36 \pm 5.04 \mathrm{~g})$ and females $(\mathrm{n}=5 ; \mathrm{SL}=11.93 \pm 1.35 \mathrm{~cm}$; weight $=29.99 \pm 8.74 \mathrm{~g}$ ) of L. pholis. We opted for histology on frozen sections similar to Kotrschal and Palzenberger [1992], because brain surface measurements would not have revealed the details required in the present context.

The individuals were deeply anesthetized with MS-222, their SL and body weight were measured and they were then perfused transcardially via the bulbus arteriosus with a marine teleost Ringer solution to clear the vasculature, followed by a solution of $4 \%$ paraformaldehyde in $0.1 \mathrm{M}$ phosphate buffer to fix the tissues. The brains were removed from the neurocranium and postfixed overnight at $4^{\circ} \mathrm{C}$ using the same fixative solution, and transferred to $0.1 \mathrm{M}$ phosphate buffer for storage at $4^{\circ} \mathrm{C}$. Brains were embedded in gelatine and coronally sectioned at $20 \mu \mathrm{m}$ on a Microm HM $500 \mathrm{M}$ cryostat at $-22^{\circ} \mathrm{C}$. The sections were mounted in series and stained with cresyl violet.

All slides were coded so that the observer who quantified the different brain areas did not know the identity of the fish to which each slide corresponded. Size of brain nuclei was measured by capturing images from an Olympus Stereomicroscope (Olympus BX 50) with a digital camera (Camedia C-2020 Z). The outlines of the regions in question were then traced using ImageTool 5.0 (Texas Health Centre, San Antonio, Tex., USA). After calibrating for magnification, the imaging program provided a measure of the area of each region. We measured all the sections of each brain from its most rostral part until the end of the telencephalon $(P$. parvicornis: $86 \pm 5.2$ sections; L. pholis: $110.2 \pm 3.5$ sections). The rostral margin of the anterior commissure was used as a reference point.

In this study, we concentrated on the dorsolateral areas of the telencephalon since recent evidence suggests an involvement of these regions in the resolution of spatial tasks [Vargas et al., 2000]. Thus, we measured the pars dorsalis (DLd), the DLv and the pars posterior (Dp) of the area dorsalis of the telencephalon [nomenclature according to Northcutt and Braford, 1980]. For reasons explained above, we also measured the nucleus olfactorius anterior of the olfactory bulb. Left- and right-side measurements were averaged for each structure.

The volume of each region was calculated by adding the measured areas which were multiplied by the thickness of each section $(20 \mu \mathrm{m})$ and expressed as $\mu \mathrm{m}^{3}$. The volume of the whole telencephalon was also computed. Since we found a positive correlation between body size and telencephalon volume ( $P$. parvicornis: $\mathrm{r}=0.87$; . pholis: $\mathrm{r}=0.71)$, we expressed all volume measurements of the different regions as a percentage of total telencephalon size, with the exception of the nucleus olfactorius anterior, in which case the volume was expressed as a percentage of the $\mathrm{SL}^{3}$.

\section{Results}

\section{Home Ranges}

During the breeding season, P. parvicornis and L. pholis males presented significantly smaller home ranges than females (Mann-Whitney U test: $P$. parvicornis: $\mathrm{Z}=$ 3.693, p < 0.001; L. pholis: $\mathrm{Z}=4.189$, $\mathrm{p}<0.001$, fig. 2). Males of $P$. parvicornis presented a maximal distance that ranged from 0 to $0.47 \mathrm{~m}$, with one outlier that reached $216.1 \mathrm{~m}$ (mean $\pm \mathrm{SE}: 6.52 \pm 6.35 \mathrm{~m}, \mathrm{n}=34$ ), while maximal distance for females ranged from 2.7 to $328.1 \mathrm{~m}$ (mean \pm SE: $128.63 \pm 64.98 \mathrm{~m}, \mathrm{n}=6$ ). In L. pholis, the range of maximum distance presented by the males is between 0 and $1 \mathrm{~m}$ (mean \pm SE: $0.32 \pm 0.07 \mathrm{~m}, \mathrm{n}=22$ ) and females present maximum distances between 0.3 and $3 \mathrm{~m}$ $($ mean \pm SE: $1.01 \pm 0.12 \mathrm{~m}, \mathrm{n}=24)$.

\section{The Blenniid Telencephalon}

Since there are no available descriptions of the forebrain of these two species in the literature, a short description is provided before presenting the quantitative results. The telencephalon of $P$. parvicornis and L. pholis has many features in common with other teleosts [Kotrschal et al., 1998], and all major divisions are clearly recognizable. The telencephalic areas were determined based only on the cytoarchitectural analysis. Since no connectional or immunohistochemical data are available for these species, no further subdivision of the main areas was established. Both species present a dorsal area more developed than the ventral area, with some dorsal areas positioned ventrally to the ventral areas (fig. 3). The most rostral part of the brain is composed of sessile olfactory bulbs, i.e. fused in the posterior area with the rostroventral telencephalon, and connected to the olfactory epithelium by a long olfactory nerve. The nucleus olfactorius 


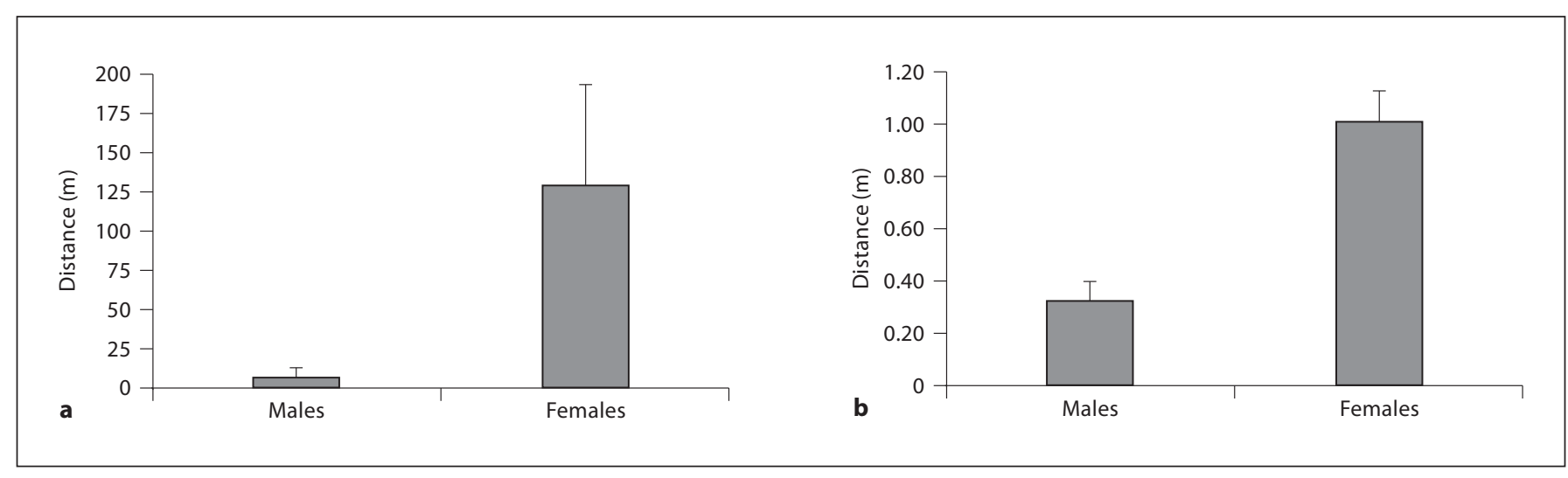

Fig. 2. Home ranges of P. parvicornis (a) and L. pholis (b). Bars represent mean values; error bars represent standard error. See Results for statistical comparisons.

anterior is positioned in the dorsal part of the olfactory bulb (fig. 3a). The medial ventral and dorsal lateral regions of this structure correspond respectively to the medial and lateral olfactory tracts, which in other species project to the telencephalon and posterior regions of the brain. The ventral caudal region of the olfactory bulb is designated nervus terminalis, a nucleus of cells with neurosecretory functions.

The dorsal telencephalon of actinopterygians is generally believed to correspond to the pallium, while the ventral telencephalon is generally considered to be homologous to the subpallium of tetrapods [Nieuwenhuys and Meek, 1990]. The pallium (dorsal telencephalon) of both species is characterized by extensive lateral, medial (Dm), and central (Dc) divisions with many distinct cell groups, and large, but more uniform dorsal and $\mathrm{Dp}$ divisions. The $\mathrm{Dm}$ area presents high cell density structured in columns. The DLv present low cell density, while the DLd present an intermediate cell density. Dc is characterized by its larger and more dispersed neurons (fig. 3 ). Since a clear distinction between dorsal division and Dc is not evident in these species, they were considered as a whole. At the level of the anterior commissure, composed of bundles of decussating axons between the two telencephalic hemispheres, Dc presents the maximal density of fibers (fig. 3c). At this level, the division between the dorsal and ventral telencephalon is clear through a fiber sheet, the lamina terminalis. At the level of the anterior commissure, the DLv and DLd areas present their cells arranged in cortical columns. It was not possible to clearly distinguish the nucleus taenia, and since it is located in the border of both DLv and Dp, it is necessarily integrat- ed in one of these areas. At the caudal region of the telencephalon, the two species acquire distinct features: while in the shanny the precommissural pattern is maintained, in the rock-pool blenny the hemispheres become coalescent and the Dc and Dm areas of each hemisphere become fused (fig. $3 \mathrm{~d}, \mathrm{e}$ ). In both species a new area emerges, the area Dp located ventrally between the DLv and lateral nuclei (Vl) (fig. 3d).

In the ventral telencephalon, it is possible to distinguish four main cell groups in the periventricular region, the ventral $(\mathrm{Vv})$, dorsal $(\mathrm{Vd})$, supracommissural, and postcommissural $(\mathrm{Vp})$ nuclei. Rostral to the anterior commissure, the ventral telencephalon consists of $\mathrm{Vd}, \mathrm{Vv}$, $\mathrm{Vl}$, and central/commissural (Vc). In both species the Vc, Vl, and intermediate nuclei are also observed (fig. 3b). Near the anterior commissure, ventrally to area ventralis, the preoptic area (POA) starts to emerge. At the level of the anterior commissure, the $\mathrm{Vd}$ is replaced by the area ventralis supracommissuralis (fig. 3c), which is then replaced more caudally by the area $\mathrm{Vp}$. At the level of the anterior commissure, both $\mathrm{Vc}$ and $\mathrm{Vl}$ are replaced by the area ventralis intermedia located ventrally to the $\mathrm{Vp}$ (fig. 3d).

\section{Quantification of Telencephalic Nuclei}

The nucleus olfactorius anterior of the olfactory bulb is significantly larger in females than in males of the rockpool blenny, but there is no significant difference between the sexes in the shanny (table 1). Although sex differences in body size (i.e. SL) are only detected in the rock-pool blenny, and the total telencephalon is larger in males of rock-pool blenny and in females of shanny, no sex differ- 
Fig. 3. Cross sections of the telencephalon and olfactory bulb from $P$. parvicornis (right) and $L$. pholis (left). Cresyl violet staining is shown on the left and a schematic illustration of the figure is drawn on the right. The rostral-caudal distance of each section from the rostral margin of the anterior commissure is the following: $L$. pholis: $-1,080 \mu \mathrm{m}$; P. parvicornis: $-1,120$ $\mu \mathrm{m}(\mathbf{a}) ;-400 \mu \mathrm{m}(\mathbf{b}) ;$ L. pholis: $+80 \mu \mathrm{m} ; P$. parvicornis: $0 \mu \mathrm{m} \quad$ (c); $+500 \mu \mathrm{m} \quad(\mathbf{d})$; L. pholis: $+740 \mu \mathrm{m}$; P. parvicornis: +900 $\mu \mathrm{m}(\mathbf{e})$.

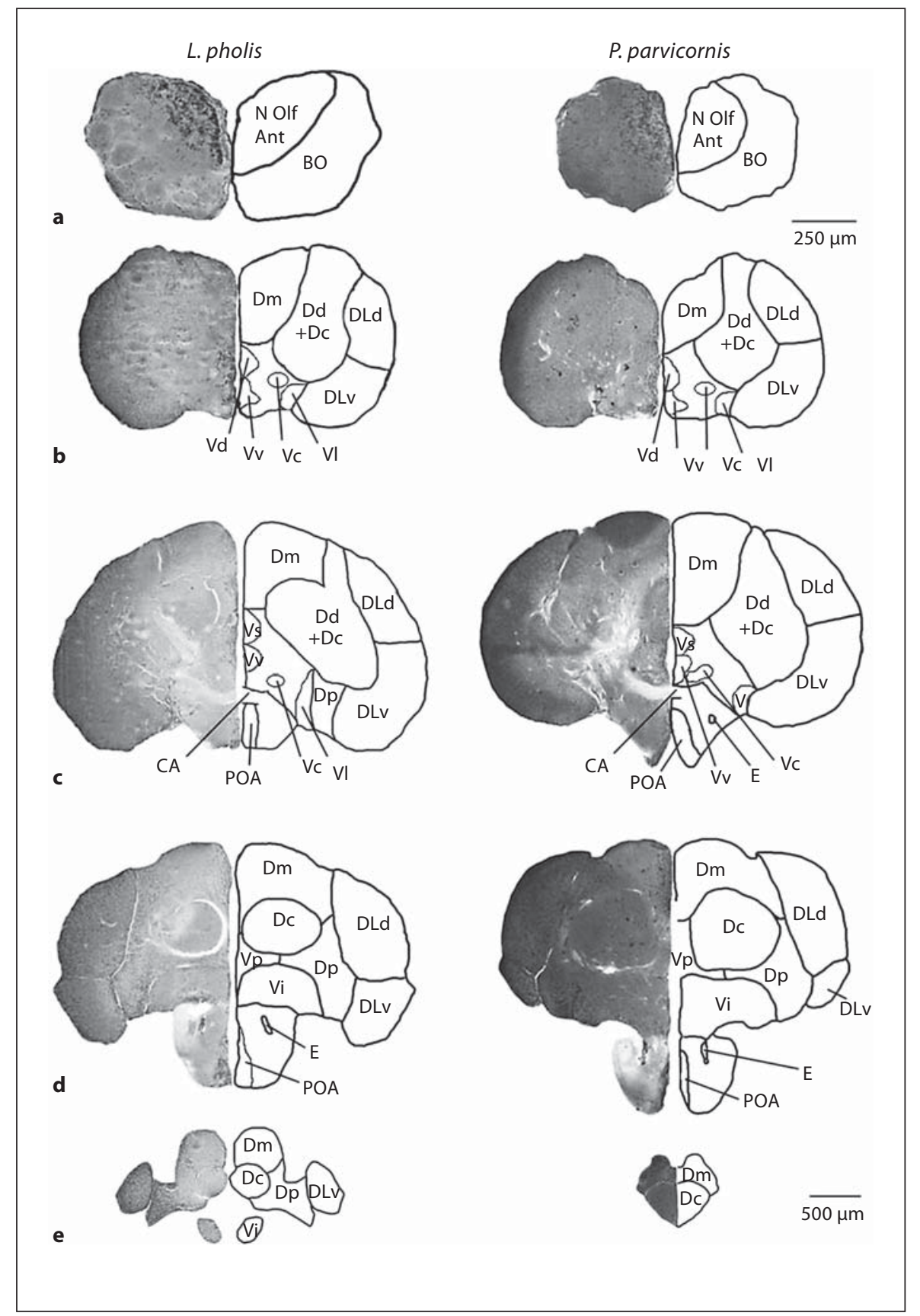

ences are observed in the volume of the telencephalon when corrected for body size, i.e. $\mathrm{SL}^{3}$ (table 1).

Among the dorsolateral areas of the telencephalon, only the DLv shows a significant sex difference in both species with females having relative larger areas than males (table 1). No significant differences were observed between the two species in the size of the DLv (MannWhitney $U$ test: $Z=-0.302 ; p=0.762$ ).

\section{Discussion}

Our results show that the anterior olfactory nucleus is only larger in females of the species with specialized pheromone production while the DLv telencephalic region is larger in females of both species. These results taken together suggest that the sex differences found in the nucleus olfactorius of the rock-pool blenny are prob- 
Table 1. Sex differences ( $Z$ values from Mann-Whitney $U$ tests) in body size and brain measurements in P. parvicornis and L. pholis

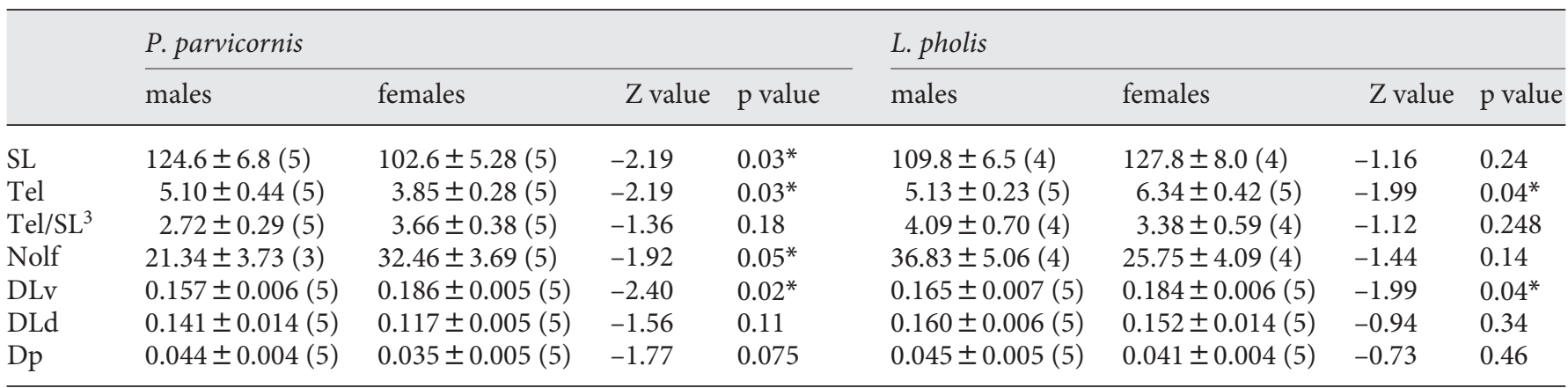

Values are expressed as mean \pm SE. Figures in parentheses represent number. $\mathrm{SL}=$ Standard length $(\mathrm{cm}) ; \mathrm{Tel}=$ volume of the telencephalon $\left(\mathrm{E}+9 \mu \mathrm{m}^{3}\right) ; \mathrm{Tel} / \mathrm{SL}^{3}=$ relative volume of the telencephalon corrected for $\mathrm{SL}^{3}\left(\mathrm{E}+3 \mu \mathrm{m}^{3} \mathrm{~cm}^{-3}\right)$; Nolf = nucleus olfactorius anterior; DLv = ventral subdivision of area dorsalis telen-

cephali lateralis; DLd = dorsal subdivision of area dorsalis telencephali lateralis; $\mathrm{Dp}=$ area dorsalis telencephali pars posterior. The volume of each nuclei is presented as the relative value of the total volume of the telencephalon (DLv, DLd and Dp) or of the $(\mathrm{SL})^{3}$ (Nolf). Significant differences are indicated with *. ably related to a specialization in chemical processing by females whereas the sex differences detected in the DLv of both species cannot be explained by the same factor alone, since in the shanny, in which males lack the anal gland, the DLv region is still larger in females.

We also documented a large sex difference in home range size in both species, and therefore the abovementioned sex difference in the DLv region of both species might be related to differences in spatial abilities between males and females. In L. pholis, the dispersal seems to be more restricted in both sexes when compared to the rockpool blenny, but the different methods used to estimate home range sizes in these two species prevent a direct comparison of the estimates.

The DLv in fish seems to be involved in spatial learning and memory in a similar manner to the role of the hippocampus in birds and mammals [Vargas et al., 2000; Portavella et al., 2002; Vargas et al., 2006]. The size of the telencephalon of African cichlids is known to be correlated with the spatial complexity of the habitat [van Staaden et al., 1995] and to the species mating system [Pollen et al., 2007]. Moreover, telencephalon ablation impairs spatial learning [Salas et al., 1996; López et al., 2000; Durán et al., 2008] and short-term memory retention [Ohnishi, 1997] in goldfish. More specifically, lateral pallium ablations selectively impair the encoding of geometric spatial information of environmental space [Rodríguez et al., 2002; Vargas et al., 2006]. Finally, learning of a spatial task in goldfish induces protein synthesis in dorsolateral telencephalic neurons but not in other areas of the telencephalon [Vargas et al., 2000]. Interestingly, this is the same area where we find the sexually dimorphic nuclei in both species of blennies.

In closely related species of voles, a similar situation has been described but with the reversed sex difference. In the polygynous meadow vole, males have larger home ranges than females [Gaulin and FitzGerald, 1986, 1989], and this difference in home ranges has neural and cognitive correlates: males have a larger hippocampus and are better at solving spatial tasks than females [Jacobs et al., 1990; Galea et al., 1996; Kavaliers et al., 1998]. In monogamous pine voles, no sex differences in home ranges are present and concomitantly there are no sex differences, either in spatial abilities or in hippocampus volume [Gaulin et al., 1990; Jacobs et al., 1990; Galea et al., 1996].

The reproductive strategy of blenniid species favors the existence of a sex-biased dimorphism in the DLv area and ultimately in spatial cognitive strategies similarly to the abovementioned example. Blenniids share several reproductive and ecological traits that predispose them to the action of sexual selection: (1) a promiscuous mating system, (2) a demersal spawning strategy (i.e. spawning occurs in a substratum with the establishment of a nest), with external fertilization, and (3) the establishment of breeding territories and the occurrence of paternal care of the eggs by males [Neat and Lengkeek, 2009]. Since malemale competition for nest sites and egg predation is usually high, male home ranges are restricted to regions close to their nest location. Their feeding intensity decreases significantly during the breeding season when compared to females [Santos and Almada, 1988; Almada et al., 1992; Santos et al., 1996; Gonçalves and Almada, 1997]. In con- 
trast, females must locate suitable males with adequate nests to spawn and therefore utilize larger areas, presenting a more extensive home range. There are multiple pieces of evidence that females mate in a nonrandom fashion [Neat and Lengkeek, 2009] and this requires good navigation and spatial abilities. For example, in a related blenniid species that also breeds in the intertidal zone (the peacock blenny, Salaria pavo), ripe females visit several nests and in some cases return to previously visited males, and mate choice decisions are based on the quality of the males encountered [Fagundes et al., 2007]. These observations suggest that females can recall their male searching excursions, and have a spatial map of the location of suitable nest sites in their area. Moreover, in other blenniid species (Ophioblennius atlanticus), feeding territories of the females can be located at significant distances from the nest sites of the males [Reynolds and Côté, 1995], suggesting again that during the breeding season blenniid females are under higher selective pressure than males for spatial abilities. For these reasons, it seems reasonable to hypothesize that in blenniids the enlargement of the DLv in females may result from sexual selection.

A more definitive test of this hypothesis requires the collection of data on a larger number of species and in particular the comparison of phylogenetically closely related species that differ in the presence of sex difference (i.e. species with females with larger home ranges than males vs. species with no sex difference in their home range). To our knowledge, this contrast is not possible in blenniids since males are always the sex that provides parental care and therefore are always more site-attached than females. However, the occurrence of alternative reproductive tactics in some blenniid species [e.g. peacock blenny, S. pavo, reviewed in Oliveira et al., 2009] offers the possibility of comparing parasitic (e.g. sneaker) males with nest holders to further test this hypothesis at the intraspecific level.

Another topic that needs to be clarified in future studies is the seasonal plasticity of the observed sex difference in the DLv, since the sex difference in home ranges between the sexes is only expected to occur during the breeding season. Moreover, in order to further corroborate the functional involvement of the DLv enlargement with an increased spatial ability, behavioral tests should be made in these blenniid species to determine if spatial performance of females and males in allocentric spatial tasks is correlated with the sexual dimorphism presented here.

In summary, we describe a sex difference in the DLv region of the telencephalon of blenniid fish that is compatible with a role of this region in spatial cognition. These results are in accordance with the sexual selection theory already tested in mammals and birds [for a review, see Jacobs, 2009], where the relative larger hippocampal structure occurs in the sex, in which successful competition required a more developed spatial orientation and enlarged home ranges.

\section{Acknowledgements}

The authors thank Ricardo Serrão Santos (Departamento de Oceanografia e Pescas, Universidade dos Açores) for hosting us during the field work on the rock-pool blenny. This work was funded by an Austrian-Portuguese bilateral research grant awarded to R.F.O. and K.K. and by the Pluriannual Programme of the Portuguese Foundation for Science and Technology (FCT R\&D Unit 331/2001). During this project, S.C. was being supported by an FCT postdoctoral fellowship (SFRH/BPD/30367/2006).

\section{References}

-Almada F, Almada V, Guillemaud T, Wirtz P (2005): Phylogenetic relationships of the north-eastern Atlantic and Mediterranean blenniids. Biol J Linn Soc 86:283-295.

-Almada VC, Gonçalves EJ, Oliveira RF, Barata EN (1992): Some features of the territories in the breeding males of the intertidal blenny Lipophrys pholis (Pisces: Blenniidae). J Mar Biol Ass UK 72:187-197.

- Barata EN, Serrano RM, Miranda A, Nogueira A, Nogueira R, Hubbard PC, Canário AVM (2008): Putative pheromones from the anal glands of male Blennies attract females and enhance male reproductive success. Anim Behav 75:379-389.
Bass AH (1981): Telencephalic efferents in channel catfish, Ictalurus punctatus: projections to the olfactory bulb and optic tectum. Brain Behav Evol 19:1-16.

Braford MR Jr (1995): Comparative aspects of forebrain organization in the ray-finned fishes: touchstones or not. Brain Behav Evol 46:259-274.

Clayton NS, Reboreda JC, Kacelnik A (1997): Seasonal changes of hippocampus volume in parasitic cowbirds. Behav Processes 41:237243.
Davis ER, Robin C, Morris J, Kaufman B (1981): Telencephalon of the teleost Macropodus: experimental localization of secondary olfactory areas and of components of the lateral forebrain bundle. Behav Neural Biol 33:257279.

Day LB, Crews D, Wilczynski W (1999a): Relative medial and dorsal cortex volume in relation to foraging ecology in congeneric lizards. Brain Behav Evol 54:314-322.

Day LB, Crews D, Wilczynski W (1999b): Spatial and reversal learning in congeneric lizards with different foraging strategies. Anim Behav 57:393-407. 
Day LB, Crews D, Wilczynski W (2001): Effects of medial and dorsal cortex lesions on spatial memory in lizards. Behav Brain Res 118:2742.

-Durán E, Ocańa FM, Gómez A, Jiménez-Moya F, Broglio C, Rodríguez F, Salas C (2008): Telencephalon ablation impairs goldfish allocentric spatial learning in a 'hole-board' task. Acta Neurobiol Exp (Wars) 68:519-525.

-Eisthen HL (1997): Evolution of vertebrate olfactory systems. Brain Behav Evol 50:222-233.

-Fagundes T, Gonçalves DM, Oliveira RF (2007): Female mate choice and mate search tactics in a sex role reversed population of the peacock blenny, Salaria pavo (Risso, 1810). J Fish Biol 71:77-89.

-Finger TE (1980): Nonolfactory sensory pathway to the telencephalon in a teleost fish. Science 210:671-673.

-Galea LA, Kavaliers M, Ossenkopp KP (1996): Sexually dimorphic spatial learning in meadow voles Microtus pennsylvanicus and deer mice Peromyscus maniculatus. J Exp Biol 199:195-200.

Galea LA, McEwen BS (1999): Sex and seasonal differences in the rate of cell proliferation in the dentate gyrus of adult wild meadow voles. Neuroscience 89:955-964.

Gaulin SJC, FitzGerald RW (1986): Sex differences in spatial ability: an evolutionary hypothesis and test. Am Nat 127:74-88.

Gaulin SJC, FitzGerald RW (1989): Sexual selection for spatial-learning ability. Anim Behav 37:322-331.

-Gaulin SJ, FitzGerald RW, Wartell MS (1990): Sex differences in spatial ability and activity in two vole species (Microtus ochrogaster and M. pennsylvanicus). J Comp Psychol 104:8893.

Gonçalves EJ, Almada VC (1997): Sex differences in resource utilization by the peacock blenny. J Fish Biol 51:624-633.

Hoshooley JS, Sherry DF (2007): Greater hippocampal neuronal recruitment in food-storing than in non-food-storing birds. Dev Neurobiol 67:406-414.

Jacobs LF (1996): Sexual selection and the brain. Trends Ecol Evol 11:82-86.

Jacobs LF (2009): The role of social selection in the evolution of hippocampal specialization; in Tommasi L, Petersin MA, Nadel L (eds): Cognitive Biology: Evolutionary and Developmental Perspectives on Mind, Brain and Behavior. Cambridge, MIT Press, pp 17-39.

- Jacobs LF, Gaulin SJ, Sherry DF, Hoffman GE (1990): Evolution of spatial cognition: sexspecific patterns of spatial behavior predict hippocampal size. Proc Natl Acad Sci USA 87:6349-6352.

Jozet-Alves C, Modéran J, Dickel L (2008): Sex differences in spatial cognition in an invertebrate: the cuttlefish. Proc Biol Sci 275: 2049-2054
Kavaliers M, Ossenkopp KP, Galea LA, Kolb B (1998): Sex differences in spatial learning and prefrontal and parietal cortical dendritic morphology in the meadow vole, Microtus pennsylvanicus. Brain Res 810:41-47.

Kotrschal K, Palzenberger M (1992): Neuroecology of cyprinids (Cyprinidae, Teleostei): comparative, quantitative histology reveals diverse brain patterns. Environ Biol Fish 33: 135-152.

Kotrschal K, Van Staaden MJ, Huber R (1998): Fish brains: evolution and environmental relationships. Rev Fish Biol Fish 8:373-408.

Laumen J, Pern U, Blüm V (1974): Investigations on the function and hormonal regulation of the anal appendices in Blennius pavo (Risso). J Exp Zool 190:47-56.

Lavenex P, Steele MA, Jacobs LF (2000a): Sex differences, but no seasonal variations in the hippocampus of food-caching squirrels: a stereological study. J Comp Neurol 425:152166.

Lavenex P, Steele MA, Jacobs LF (2000b): The seasonal pattern of cell proliferation and neuron number in the dentate gyrus of wild adult eastern grey squirrels. Eur J Neurosci 12:643-648.

López JC, Broglio C, Rodríguez F, Thinus-Blanc C, Salas C (2000): Reversal learning deficit in a spatial task but not in a cued one after telencephalic ablation in goldfish. Behav Brain Res 109:91-98.

Neat F, Lengkeek W (2009): Sexual selection in blennies; in Patzner RA, Gonçalves EJ, Hastings PA, Kapoor BG (eds): The Biology of Blennies. Enfield, Science Publishers, pp 249-278.

Nieuwenhuys R, Meek J (1990): The telencephalon of actinopterygian fishes; in Jones EG, Peters A (eds): Cerebral Cortex. New York, Plenum Press, pp 31-73.

Northcutt RG (2006): Connections of the lateral and medial divisions of the goldfish telencephalic pallium. J Comp Neurol 494:903-943.

Northcutt RG (2008): Forebrain evolution in bony fishes. Brain Res Bull 18:191-205.

Northcutt RG, Braford MR (1980): New observations on the organization and evolution of the telencephalon of actinopterygian fishes; in Ebbesson SOE (ed): Comparative Neurology of the Telencephalon. New York, Plenum, pp 41-98.

Odling-Smee L, Simpson SD, Braithwaite VA (2006): The role of learning in fish orientation; in Brown C, Laland K, Krause J (eds): Fish Cognition and Behavior. Oxford, Blackwell, pp 119-138.

Ohnishi K (1997): Effects of telencephalic ablation on short-term memory and attention in goldfish. Behav Brain Res 86:191-199.

Oliveira RF, Gonçalves DM, Ros AFH (2009): Evolution and development of alternative reproductive tactics in blennies: a tale of two species; in Patzner R, Hastings P, Gonçalves EJ, Kapoor BG (eds): The Biology of Blennies. Enfield, Science Publishers, pp 279-308.
Patzner RA (1984): Individual tagging of small fish. Aquaculture 40:251-253.

-Pollen AA, Dobberfuhl AP, Scace J, Igulu MM, Renn SC, Shumway CA, Hofmann HA (2007): Environmental complexity and social organization sculpt the brain in Lake Tanganyikan cichlid fish. Brain Behav Evol 70:21-39.

Portavella M, Vargas JP, Torres B, Salas C (2002): The effects of telencephalic pallial lesions on spatial, temporal, and emotional learning in goldfish. Brain Res Bull 57:397-399.

Puts DA, Gaulin SJ, Breedlove SM (2007): Sex differences in spatial ability: evolution, hormones and the brain; in Platek SM, Keenan JP, Shackelford TK (eds): Evolutionary Cognitive Neuroscience. Cambridge, MIT Press, pp 329-379.

Reboreda JC, Clayton NS, Kacelnik A (1996): Species and sex differences in hippocampus size in parasitic and non-parasitic cowbirds. Neuroreport 7:505-508.

Reynolds JD, Côté IM (1995): Direct selection on mate choice - female redlip blennies pay more for better mates. Behav Ecol 6:175-181.

Rodríguez F, López JC, Vargas JP, Gómez Y, Broglio C, Salas C (2002): Conservation of spatial memory function in the pallial forebrain of reptiles and ray-finned fishes. J Neurosci 22:2894-2903

-Rooney D, Dǿving KB Ravaille-Veron M, Szabo $T$ (1992): The central connections of the olfactory bulbs in cod, Gadus morhua L. J Hirnforsch 33:63-75.

-Salas C, Broglio C, Rodríguez F, López JC, Portavella M, Torres B (1996): Telencephalic ablation in goldfish impairs performance in a 'spatial constancy' problem but not in a cued one. Behav Brain Res 79:193-200.

Santos RF (1986): Capacidade de retorno à área vital, padrão de dispersão e organização social em Blennius sanguinolentus Pallas (Pisces: Blenniidae) durante a época de reprodução. Psicologia 5:121-131.

Santos RS, Almada V (1988): Intraspecific variations in reproductive tactics in males of the rocky intertidal fish Blennius sanguinolentus in the Azores; in Chelazzi G, Hartnoll R, Vannini M (eds): Behavioral Adaptation to Intertidal Life. New York, Plenum Press, pp 421-447.

Santos RS, Almada VC, Santos AJF (1989): Field experiments and observations on homing and territoriality in intertidal blennies; in Blanchard RJ, Brain PF, Blanchard DC, Parmigiani S (eds): Ethoexperimental Approaches to the Study of Behaviour. Dordrecht, Kluwer Academic Publishers, pp 623 632.

-Santos RS, Hawkins SJ, Nash RDM (1996): Reproductive phenology of the Azorean rock pool blenny, a fish with alternative mating tactics. J Fish Biol 48:842-858.
Sex Differences in the Dorsolateral

Telencephalon in Blenniid Fish 
Santos RS, Nash RDM, Hawkins SJ (1995): Age, growth and sex ratio of the Azorean rockpool blenny, Parablennius sanguinolentus parvicornis. J Mar Biol Ass UK 75:751-754.

- Sherry DF, Forbes MR, Khurgel M, Ivy GO (1993): Females have a larger hippocampus than males in the brood-parasitic brownheaded cowbird. Proc Natl Acad Sci USA 90: 7839-7843.

Shumway CA (2008): Habitat complexity, brain, and behavior. Brain Behav Evol 72:123-134.

-Sovrano VA, Bisazza A, Vallortigara G (2003): Modularity as a fish (Xenotoca eiseni) views it: conjoining geometric and nongeometric information for spatial reorientation. J Exp Psychol Anim Behav Process 29:199-210.
Taborsky M, Limberger D (1980): The activity rhythm of Blennius sanguinolentus Pallas, an adaptation to its food source? PSZNI Mar Ecol 1:143-153.

van Staaden MJ, Huber R, Kaufman LS, Liem KF (1995): Brain evolution in cichlids of the African Great Lakes: brain and body size, general patterns, and evolutionary trends. Zoology $98: 165-178$.

Vargas JP, Bingman VP, Portavella M, López JC (2006): Telencephalon and geometric space in goldfish. Eur J Neurosci 24:2870-2878.

Vargas JP, Rodríguez F, López JC, Arias JL, Salas C (2000): Spatial learning-induced increase in the argyrophilic nucleolar organizer region of dorso-lateral telencephalic neurons in goldfish. Brain Res 865:77-84. von Bartheld CS, Meyer DL, Fiebig E, Ebbesson SO (1984): Central connections of the olfactory bulb in the goldfish, Carassius auratus. Cell Tissue Res 238:475-487.

Weltzien FA, Höglund E, Hamdani EH, Døving KB (2003): Does the lateral bundle of the medial olfactory tract mediate reproductive behavior in male crucian carp? Chem Senses 28:293-300.

Wullimann MF, Mueller T (2004): Teleostean and mammalian forebrains contrasted: evidence from genes to behavior. J Comp Neurol 475:143-162.

Zander CD (1975): Secondary sex characteristics of Blennioid fishes (Peciformes). Pubbl Stat Zool Napoli 39(suppl):717-727. 